\title{
KEEFFEKTIFAN MATA KULIAH BAHASA ARAB SEBAGAI MATA KULIAH UMUM DI STAIN GAJAH PUTIH TAKENGON
}

\author{
Andika Hariyanto Surbakti \\ STAIN Gajah Putih Takengon, Aceh Tengah, Aceh \\ Email: andikahariyanto_surbakti@yahoo.com
}

\begin{abstract}
Abstrak. Penelitian ini bertujuan untuk mendeskripsikan keefektifan mata kuliah bahasa Arab sebagai mata kuliah umum di STAIN GPA. Penelitian ini merupakan penelitian survei. Responden dalam penelitian ini adalah 100 mahasiswa dan 6 dosen pengampu mata kuliah Bahasa Arab. Teknik pengumpulan data yang digunakan adalah kuesioner, pengamatan, dan wawancara. Hasil penelitian ini adalah secara umum Bahasa Arab sebagai mata kuliah umum di STAIN GPA tidak efektif karena kurangnya dukungan institusi dan dosen, tidak tersedianya kurikulum program yang jelas, dan rendahnya tingkat kepuasan kerja baik dosen maupun mahasiswa.
\end{abstract}

Kata kunci: Bahasa Arab, Mata Kuliah Umum.

\section{Pendahuluan}

Bahasa merupakan alat komunikasi atau alat interaksi yang dimiliki oleh manusia untuk menyampaikan pikiran, gagasan, konsep, atau perasaan. Bahasa sebagai alat komunikasi sekaligus sebagai alat untuk menunjukkan identitas diri. Melalui bahasa, kita dapat menunjukkan sudut pandang kita, pemahaman kita atas sesuatu hal, asal-usul bangsa dan negara kita, pendidikan bahkan sifat kita. Bahasa menjadi cermin bagi diri kita, baik sebagai bangsa maupun sebagai individu. Bahasa arab merupakan salah satu dari tiga bahasa yang paling banyak digunakan oleh manusia. Oleh karena itu tentunya bahasa ini sangatlah familiar bagi seluruh bangsa di belahan bumi manapun. Dalam perkembangannya bahasa arab bukan lagi sekedar bahasa sehari-hari, tetapi bahasa ini juga sering menjadi objek penelitian baik sosial maupun dalam bidang pendidikan dikarekan keunikan dan kelebihannya.

Bagi umat islam bahasa arab merupakan bahasa yang digunakan dalam ibadah maupun dalam interaksi sosial sehingga bagi bangsa yang mayoritas muslim seperti Indonesia, bahasa arab menjadi sangat penting untuk dipelajari maupun diteliti lebih dalam. Berdasarkan hal itu dalam undang-undang pendidikan nasional, bahasa arab menjadi salah satu bagian yang harus dijadikan pembelajaran yang wajib bagi seluruh siswa maupun mahasiswa. Dalam pelaksanaannya tentu banyak metode-metode yang digunakan untuk mengefektifkan pembelajaran tersebut.

STAIN Gajah Putih merupakan salah satu lembaga pendidikan yang mewajibkan seluruh mahasiswanya untuk mempelajari Bahasa Arab sebagai mata kuliah umum yang di ajarkan selama satu semester. Dalam pelaksanaannya pembelajaran tersebut menggunakan metode-metode pembelajaran bahasa yang sesuai dengan kurikulum kampus. Diharapkan setelah melaksanakan pembelajaran bahasa arab ini mahasiswa mampu mengaplikasikan bahasa arab tersebut dalam ibadah, interaksi sosial maupun dalam penelitian yang relevan. 
Dalam pelaksaannya masih banyak kendala yang dihadapi baik itu dari materi maupun native speaker yg belum memadai. Banyaknya mahasiswa STAIN GPA yang bukan lulusan pesantren juga membuat pembelajaran bahasa arab menjadi kurang diminati dikalangan mahasiswa program studi pendidikan umum. Efektifitas pembelajaran bahasa arab menjadi sangat penting untuk diteliti sebagai dasar dalam perancangan kurikulum bahasa arab agar lebih baik kedepannya

Kopetensi berbahasa asing menjadi salah satu target dalam pendidikan tinggi. Oleh karena itu, pengembangan kemampuan berbahasa asing pada unsur kependidikan menjadi faktor penunjang keberhasilan pendidikan dan pengajaran. Pengembangan bahasa di STAIN GPA dilaksanakan oleh Unit Pelaksana Teknis melalui beberapa tahap, yaitu perencanaan, pengorganisasian, pelaksanaan, pemantauan, dan penilaian program (Panduan Akademik STAIN GPA, 2015-2016: 40). Salah satu program penunjang untuk meningkatkan kemampuan berbahasa Arab bagi mahasiswa yang telah dilaksanakan adalah mata kuliah umum Bahasa Arab.

Berdasarkan uraian di atas, peninjauan tentang keefektifan pelaksanaan mata kuliah umum bahasa Arab perlu dilaksanakan. Pertanyaan penelitan dalam penelitian ini adalah tentang bagaimana keefektifan Bahasa Arab sebagai mata kuliah umum di STAIN GPA.

\section{Metode Penelitian}

Penelitan ini adalah penelitian survei. Penelitian survei merupakan penelitian yang berusaha mengumpulkan data satu atau beberapa variabel yang diambil dari anggota populasi untuk menentukan status populasi tersebut pada saat penelitian (Gay, 1983: 155). Dengan kata lain, kesimpulan dari penelitian survey digeneralisasikan atau berlaku untuk seluruh populasi meski data hanya diperoleh dari sampel (Singleton \& Straits, 1999: 239; Neuman, 2003: 267; Endang Mulyatiningsih, 2010: 193). Responden dalam penelitian ini adalah mahasiswa dan dosen pengampu mata kuliah Bahasa Arab.

Pemilihan sample pada penelitian ini menggunakan random sampling. Teknik sampling ini digunakan untuk menjaring data mahasiswa. Menurut Brog \& Gall (via Endang Mulyatiningsih, 2011: 193) jumlah sampel penelitian deskriptif minimal 100 orang. Selain itu, Sugiono berpendapat bahwa semakin besar jumlah sampel yang diambil dapat meminimalisir kesalahan dalam mengeneralisasi (Sungkawati Kardi Wahyuningsih: 2015: 61). Berdasarkan teori tersebut, 100 orang mahasiswa dipilih sebagai sampel dalam penelitian ini. Kemudian, seluruh dosen pengampu mata kuliah Bahasa Arab yang berjumlah 6 orang merupakan sampel dalam penelitian ini.

Data dalam penelitian ini dikumpulkan melalui kuesioner, pengamatan, dan wawancara. Kuesioner dan interviu merupakan instrument-instrumen utama yang selalu digunakan sebagai alat pengumpul data atau pengumpul informasi pada penelitian survey (Singleton \& Straits, 1999: 239; Wuraji, 2006: 89). Data yang diperoleh dianalisis secara deskriptif.

\section{Hasil dan Pembahasan}

Berdasarkan panduan akademik STAIN GPA tahun 2015-2016, Bahasa Arab merupakan mata kuliah umum yang wajib ditempuh oleh seluruh mahansiswa. Pelaksanaan mata kuliah umum diatur dalam sebaran mata kuliah tiap-tiap program studi. Terdapat 11 program studi yang melaksanakan perkuliahan Bahasa Arab sebagai mata kuliah umum. 
Tabel 1. Sebaran Mata Kuliah Umum Bahasa Arab

\begin{tabular}{|c|c|c|c|c|}
\hline No. & Program Studi & $\begin{array}{l}\text { Semester } \\
\text { Pelaksanaan }\end{array}$ & $\begin{array}{l}\text { Nama } \\
\text { Kuliah }\end{array}$ & $\begin{array}{l}\text { Kode Mata } \\
\text { Kuliah }\end{array}$ \\
\hline \multirow[t]{2}{*}{1} & \multirow[t]{2}{*}{ Pendidikan Agama Islam } & 1 & Bahasa Arab 1 & 531101 \\
\hline & & 2 & Bahasa Arab 2 & 531107 \\
\hline 2 & Tadris Bahasa Inggris & 3 & Bahasa Arab & 530002 \\
\hline 3 & Tadris Matematika & 1 & Bahasa Arab & 530002 \\
\hline 4 & $\begin{array}{l}\text { Pendidikan Guru Raudhatul } \\
\text { Athfal }\end{array}$ & 1 & Bahasa Arab & 530002 \\
\hline \multirow[t]{2}{*}{5} & \multirow{2}{*}{ Managemen Pendidikan Islam } & 1 & Bahasa Arab 1 & 531602 \\
\hline & & 2 & Bahasa Arab 2 & 531607 \\
\hline \multirow[t]{2}{*}{6} & Pendidikan & 1 & Bahasa Arab 1 & 531702 \\
\hline & Ibtidaiyah & 2 & Bahasa Arab 2 & 531707 \\
\hline 7 & Ekonomi Islam & 1 & Bahasa Arab & 530002 \\
\hline 8 & Perbankan Syari'ah & 1 & Bahasa Arab & 530002 \\
\hline \multirow[t]{2}{*}{9} & \multirow[t]{2}{*}{ Hukum Tata Negara } & 1 & Bahasa Arab 1 & 532302 \\
\hline & & 2 & Bahasa Arab 2 & 532304 \\
\hline \multirow[t]{2}{*}{10} & \multirow[t]{2}{*}{ Komisi Penyiaran Islam } & 1 & Bahasa Arab 1 & 533102 \\
\hline & & 2 & Bahasa Arab 2 & 533106 \\
\hline \multirow[t]{3}{*}{11} & \multirow[t]{3}{*}{ Ilmu Al-Quran dan Tafsir } & 1 & Bahasa Arab 1 & 533201 \\
\hline & & 2 & Bahasa Arab 2 & 533208 \\
\hline & & 3 & Bahasa Arab 3 & 533216 \\
\hline 12 & Pendidikan Bahasa Arab & - & - & - \\
\hline
\end{tabular}

Program studi Pendidikan Agama Islam melaksanakan pekuliahan Bahasa Arab pada semester pertama dan kedua. Program studi Tadris Bahasa Inggris melaksanakan perkuliahan Bahasa Arab pada semester ketiga. Program studi Tadris Matematika melaksanakan perkuliahan Bahasa Arab pada semester pertama. Program studi Pendidikan Guru Raudhatul Athfal melaksanakan perkuliahan Bahasa Arab pada semester pertama. Program studi Manajemen Pendidikan Islam melaksanakan pekuliahan Bahasa Arab pada semester pertama dan kedua. Program studi Pendidikan Guru Madrasah Ibtidaiyah melaksanakan perkuliahan Bahasa Arab pada semester pertama dan kedua. Program studi Ekonomi Islam melaksanakan perkuliahan Bahasa Arab pada semester pertama. Program studi Perbankan Syari'ah melaksanakan pekuliahan Bahasa Arab pada semester pertama. Program studi Hukum Tata Negara melaksanakan perkuliahan Bahasa Arab pada semester pertama dan kedua. Program studi Komunikasi Penyiaran Islam melaksanakan perkuliahan Bahasa Arab pada semester pertama dan kedua. Sedangkan, program studi Ilmu Al-Quran dan Tafsir melaksanakan perkuliahan Bahasa Arab pada semester pertama, kedua dan ketiga. Pada program studi Pendidikan Bahasa Arab tidak dilaksanakan mata kuliah umum Bahasa Arab karena pada program studi ini mempelajari Bahasa Arab secara terperinci.

Terdapat perbedaan pelaksanaan mata kuliah umum Bahasa Arab. Lima program studi melaksanakan perkuliahan Bahasa Arab dalam satu semester. Lima program studi melaksanakan perkuliahan Bahasa Arab dalam dua semester. Satu program studi melaksanakan perkuliahan Bahasa Arab dalam tiga semester. Mata kuliah Bahasa Arab 1 mempelajari keterampilan Bahasa Arab secara umum. Sedangkan mata kuliah Bahasa Arab 2 dan 3 mempelajari bahasa Arab secara spesifik sesuai program studi yang 
ditempuh. Mata kuliah umum Bahasa Arab diampu oleh dosen yang berhome-base di program studi Pendidikan Bahasa Arab.

Keefektifan suatu program pendidikan dapat dilihat dari empat faktor, yaitu faktor institusional, faktor guru, faktor pembelajaran, dan faktor siswa (Richards, 2001: 198). Berikut merupakan pemaparan dukungan institusi dalam pelaksanaan mata kuliah umum Bahasa Arab. Institusi memberikan dukungan pada berlangsungnya perkuliahan umum secara effektif. Fasilitas belajar untuk mahasiswa disediakan. hal serupa juga dilakukan oleh institusi, yaitu menyediakan fasilitas untuk dosen pengampu mata kuliah umum Bahasa Arab, seperti memfasilitasi koordinasi dosen, pengembangan silabus, materi, dan buku ajar.

Akan tetapi, dosen pengampu mata kuliah memiliki pendapat yang berbeda terhadap dukungan institusi. Berikut merupakan pendapat dosen terhadap dukungan institusi terhadap pelaksanaan mata kuliah umum Bahasa Arab.

Tabel 2. Dukungan Institusi Terhadap Pelaksanaan Mata Kuliah Umum

\begin{tabular}{lllll}
\hline No & Indikator & Tersedia & Tidak Tersedia & Tidak Tahu \\
\hline 1 & Silabus mata kuliah & $33 \%$ & $67 \%$ & \\
2 & Materi ajar & & $100 \%$ & \\
3 & Program mengajar & & $100 \%$ & \\
4 & Evaluasi perkuliahan & & $100 \%$ & \\
5 & Ruang kuliah & $100 \%$ & & \\
6 & Akses internet & & $100 \%$ & \\
7 & Media pembelajaran & & $100 \%$ & $17 \%$ \\
8 & Pelatihan dosen & & $83 \%$ & \\
\hline
\end{tabular}

Pandangan dosen terhadap mata kuliah umum Bahasa Arab, berdasarkan hasil wawancara, $67 \%$ dosen menyatakan bahwa mereka tidak puas pada hasil pembelajaran yang dilaksanakan. Hal tersebut disebabkan oleh tidak adanya deskripsi, kisi-kisi, dan tujuan pembelajaran mata kuliah Bahasa Arab yang jelas; tidak adanya panduan pelaksanaan perkuliahan yang jelas; tidak tersedianya buku ajar, materi, dan media yang memadai; tidak adanya koordinasi antara dosen pengampu mata kuliah umum Bahasa Arab; tidak tersedianya waktu untuk menyusun materi yang sesuai dengan kebutuhan mahasiswa; tingkat penguasaan Bahasa Arab yang beragam antara satu dengan mahasiswa yang lain dalam satu kelas; motivasi belajar mahasiswa yang rendah; dan terbatasnya fasilitas yang mendukung pembelajaran.

Dilain pihak, 33\% dosen menyatakan puas terhadap perkuliahan Bahasa Arab. Kepuasan kerja tersebut dipengaruhi oleh hal-hal sebagai berikut. Pendangan bahwa mengajar mata kuliah umum diberbagai bidang keilmuan dirasa menarik. Selain itu dosen terpacu untuk mempelajari bidang ilmu sesuai bidang keilmuan mahasiswa agar materi yang diajarkan sesuai dengan kebutuhan belajar mahasiswa.

Faktor yang mempengaruhi keberhasilan suatu program pendidikan adalah pemahaman siswa terhadap program tersebut, pandangan terhadap pembelajaran, cara belajar, dan motivasi (Richards, 2001: 223-224). Selain itu, tingkat kepuasan mahasiswa dalam mengikuti pembelajaran memiliki peran penting dalam menilai kualitas pembelajaran (Jamilah, 2015: 7). Berikut adalah pemaparan tingkat kepuasan mahasiswa terhadap mata kuliah umum Bahasa Arab. 
Table 3. Indikator Tingkat Kepuasan Mahasiswa Terhadap Perkuliahan Bahasa Arab

\begin{tabular}{|c|c|c|c|c|c|c|c|c|c|}
\hline No & Indikator & $\mathrm{N}$ & 5 & 4 & 3 & 2 & 1 & Mean & SD \\
\hline 1 & Penyampaian materi & 100 & 7 & 15 & 50 & 19 & 9 & 3.24 & 1.10 \\
\hline 2 & Persiapan mengajar & 100 & 7 & 11 & 53 & 16 & 13 & 3.14 & 1.13 \\
\hline 3 & Managemen waktu & 100 & 6 & 17 & 38 & 19 & 10 & 2.89 & 1.05 \\
\hline 4 & Meningkatnya & 100 & 5 & 17 & 21 & & 11 & & \\
\hline 5 & $\begin{array}{l}\text { mahasiswa } \\
\text { Tanggapan terhadap kesulitan } \\
\text { belajar }\end{array}$ & 100 & 5 & 13 & 22 & 51 & 17 & 2.99 & 1.21 \\
\hline 6 & Kualitas isi pembelajaran & 100 & 4 & 19 & 18 & 50 & 19 & 2.99 & 1.34 \\
\hline 7 & Materi yang digunakan & 100 & 1 & 16 & 28 & 51 & 14 & 2.99 & 1.19 \\
\hline 8 & Penilaian yang adil & 100 & 3 & 4 & 32 & 58 & 3 & 2.73 & 0.85 \\
\hline 9 & Balikan yang berguna & 100 & 7 & 3 & 29 & 58 & 3 & 2.81 & 0.99 \\
\hline 10 & $\begin{array}{l}\text { Meningkatkannya kemampuan } \\
\text { bahasa }\end{array}$ & 100 & 8 & 2 & 26 & 64 & & 2.82 & 0.98 \\
\hline 11 & Kepuasan mahasiswa & 100 & & 3 & 27 & 62 & 8 & 2.50 & 0.73 \\
\hline
\end{tabular}

Pada table 3, dapat dilihat bahwa mean atau skor rata-rata dari pendapat responden pada tingkat kepuasan mahasiswa terhadap perkuliahan umum Bahasa Arab berkisar 2.50 sampai dengan 3.38 dari beberapa indikator. Nilai minimal keberterimaan dari nilai rata-rata adalah 3.00 dan nilai maksimal adalah 5.00. Maka dari itu, dapat disimpulkan bahwa tingkat kepuasan mahasiswa terhadap mata kuliah umum Bahasa Arab rendah. Selain itu, responden memiliki pendapat yang beragam terhadap pernyataan dalam kuesioner berdasarkan nilai dari standar deviasi yang cenderung tinggi.

Berdasarkan data yang diperoleh, tingkat kepuasan mahasiswa yang rendah dipengaruhi oleh proses pembelajaran yang kurang menarik minat mahasiswa, materi ajar yang kurang menarik, kurangnya tanggapan dan balikan terhadap hasil belajar mahasiswa, serta kemampuan kebahasaan yang dirasa tidak maksimal meningkat oleh mahasiswa. Sedangkan dari segi penyampaian materi dan persiapan mengajar yang dilakukan dosen pengampu mata kuliah umum, tingkat kepuasan mahasiwa tinggi.

\section{Kesimpulan}

Bahasa Arab merupakan mata kuliah umum yang wajib ditempuh oleh seluruh mahansiswa STAIN GPA yang pelaksanaannya diatur dalam sebaran mata kuliah tiaptiap program studi. Mata kuliah umum Bahasa Arab dirasa tidak efektif berdasarkan beberapa faktor, yaitu faktor institusional, faktor guru, faktor pembelajaran, dan faktor siswa. Pada faktor institusional, institusi menyediakan fasilitas belajar untuk mahasiswa dan dosen, seperti memfasilitasi koordinasi dosen, pengembangan silabus, materi, dan buku ajar. pada faktor kedua, tingkat kepuasan kerja dosen cenderung rendah karena sarana pengajaran Bahasa Arab belum memadai. Hal serupa juga terjadi pada tingkat kepuasan mahasiswa. Mahasiswa berpendapat bahwa rendahnya tingkat kepuasan mahasiswa disebabkan oleh tidak efektifnya faktor permbejaran yang mereka laksanakan.

\section{Daftar Pustaka}

Endang Mulyatiningsih. 2011. Riset Terapan. Yogyakarta: UNY Press.

Gay, L. R. 1983. Educational Research. Colombus: Charles E. Merrill Publishing Company. 
Jamilah. 2015. The Effectiveness of English as a General Course Program in Yogyakarta State University. Journal of Education. Vol.8 No. 1, 1-9.

Panduan Akademik Sekolah Tinggi Agama Islam Negeri Gajah Putih Takengon. 20152016.

Richards, J. C. 2001. Curriculum Development in Language Teaching. Cambridge: Cambridge University Press.

Neuman, W. L. 2003. Social Research Methods. Boston: Pearson Education, Inc.

Singleton, R. A. \& Straits, B. C. 1999. Approach to Social Research. New York: Oxford university Press.

Sungkawati Kardi Wahyuningsih. 2015. Grammatical Error Analysis in the Descriptive Writing of the Semester 3 Students of English Education Department of STAIN Gajah Putih. Journal of Education. Vol.8 No. 1, 60-65.

Wuraji. 2006. Panduan Penelitian Survei. Yogyakarta: Lembaga Penelitian UNY. 